\title{
Aggregation Quenching in Thin Films of MEH-PPV Studied by Near-Field Scanning Optical Microscopy and Spectroscopy
}

Th. Huser, M. Yan

This article was submitted to Materials Research Society Spring 2000 Meeting San Francisco, CA, April 24-28, 2000

\section{April 11, 2000}

U.S. Department of Energy

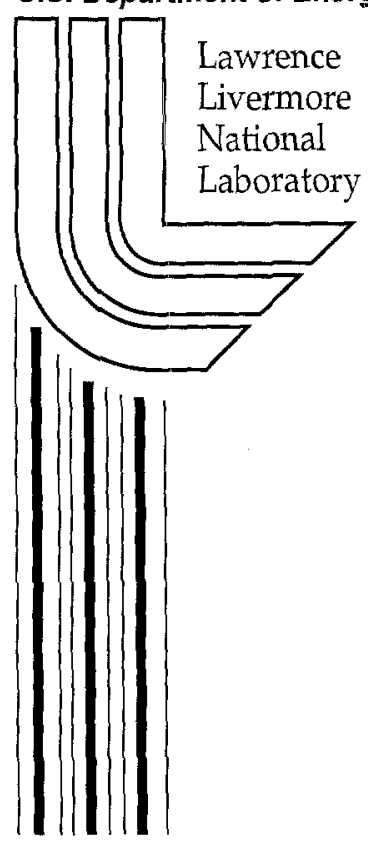




\section{DISCLAIMER}

This document was prepared as an account of work sponsored by an agency of the United States Government. Neither the United States Government nor the University of California nor any of their employees, makes any warranty, express or implied, or assumes any legal liability or responsibility for the accuracy, completeness, or usefulness of any information, apparatus, product, or process disclosed, or represents that its use would not infringe privately owned rights. Reference herein to any specific commercial product, process, or service by trade name, trademark, manufacturer, or otherwise, does not necessarily constitute or imply its endorsement, recommendation, or favoring by the United States Government or the University of California. The views and opinions of authors expressed herein do not necessarily state or reflect those of the United States Government or the University of California, and shall not be used for advertising or product endorsement purposes.

This is a preprint of a paper intended for publication in a journal or proceedings. Since changes may be made before publication, this preprint is made available with the understanding that it will not be cited or reproduced without the permission of the author.

This report has been reproduced directly from the best available copy.

Available electronically at http://www.doc.gov/bridge

Available for a processing fee to U.S. Department of Energy

And its contractors in paper from

U.S. Department of Energy

Office of Scientific and Technical Information

P.O. Box 62

Oak Ridge, TN 37831-0062

Telephone: (865) 576-8401

Facsimile: (865) 576-5728

E-mail: reports@adonis.osti.gov

Available for the sale to the public from

U.S. Department of Commerce

National Technical Information Service 5285 Port Royal Road

Springfield, VA 22161

Telephone: (800) 553-6847

Facsimile: (703) 605-6900

E-mail: orders@ntis.fedworld.gov

Online ordering: http://www.ntis.gov/ordering.htm

\section{OR}

Lawrence Livermore National Laboratory

Technical Information Department's Digital Library

http://www.llnl.gov/tid/Library.html 


\title{
Aggregation quenching in thin films of MEH-PPV studied by near-field scanning optical microscopy and spectroscopy
}

\author{
Th. Huser ${ }^{1}$ and M. Yan \\ Department of Chemistry and Materials Science, Lawrence Livermore National \\ Laboratory, M/S L-250, Livermore, CA 94551, U.S.A.
}

Keywords: NSOM, photoluminescence, MEH-PPV, conjugated polymers, aggregates

\begin{abstract}
Aggregates in thin films of conjugated polymers form excimer states and significantly reduce the photo- and electroluminescence efficiency in devices produced from these materials. We have studied the aggregate formation in thin films of MEH-PPV by nearfield scanning optical microscopy and spectroscopy. Local photoluminescence spectroscopy and photo-bleaching experiments have been used to show that thin films of MEH-PPV are homogeneously aggregated and do not form aggregated domains.
\end{abstract}

\section{Introduction}

Solution processable conjugated polymers have lately seen a remarkable amount of research activity because of their potential for simplified production of large-scale electroluminescent devices ${ }^{1}$. Their similarity to organic dyes together with their electron transport properties makes them promising candidates for applications such as lightemitting diodes, lasers and thin-film transistors. However, some of this potential is significantly decreased by the tendency of polymers to form aggregates. Aggregation of polymer chains opens a channel for interchain excitons and therefore decreases electroluminescence and photoluminescence (PL) efficiency in conjugated polymers ${ }^{2,3}$.

Near-field scanning optical microscopy (NSOM) has become a versatile tool to study optical properties of thin films and membranes with sub-wavelength optical resolution along with surface topography ${ }^{4,5}$. NSOM is based on the principle that any material if it is being brought into the near-field of a sub-wavelength light source can be imaged with a spatial resolution determined mostly by the size of the light source and its distance to the sample. In NSOM this is conveniently achieved by using tapered and aluminum-coated optical fiber tips as light sources. Such tips are routinely fabricated with aperture diameters on the order of a few $10 \mathrm{~nm}$. NSOM has recently been applied to thin films of

\footnotetext{
1 To whom correspondence should be addressed. Electronic mail: huser1@1lnl.gov
} 
conjugated polymers to study the local photoluminescence ${ }^{6,7,8,9}$, polarization behavior of stretch oriented films ${ }^{8,9}$ and polymer domains ${ }^{7,10}$, local photobleaching ${ }^{11}$, photoconductivity ${ }^{12}$ and domains in polymer blends ${ }^{13,14,15}$. Blatchford et al. ${ }^{7}$ have used polarization contrast NSOM of the PL emission to determine the domain size of aggregates in films of PPyV to about $200 \mathrm{~nm}$. However, no near-field spectroscopic data on the aggregate formation have been provided.

Here, we have used NSOM spectroscopy to study aggregation quenching in thin films of poly[2-methoxy,5-(2'-ethyl-hexyloxy)-p-phenylene-vinylene] (MEH-PPV). Aggregates in MEH-PPV have been shown to form excimers ${ }^{2,3}$. The formation of excimers leads to a significant reduction in PL quantum yield of thin films and therefore to a reduced efficiency of electroluminescent conjugated polymer devices. So far, it is still unknown if aggregates in MEH-PPV films form domains within the film or if the aggregation is uniform throughout the film.

\section{Experimental}

In our NSOM setup, the $514.5 \mathrm{~nm}$ line of an argon ion laser was coupled into the NSOM fiber tip. Samples were held above the tip on a piezo tube scanner with a maximum horizontal scan range of $30 \mu \mathrm{m}$ and $3 \mu \mathrm{m}$ vertical. The local photoluminescence excited by the tip was collected with a $100 x$ dry objective, 0.8 numerical aperture, held in a standard upright optical microscope. The photoluminescence was separated from the excitation light by a color glass long pass filter (OG530, Schott) and then focused onto a photon-counting avalanche photodiode (SPCM-AQ-141, EG\&G). To obtain images of parts of the emission spectrum, additional band pass filters could be inserted in the beam path by a remote controlled filter wheel. The pulses from the counting photodiode were fed in the counting board of a scanning probe microscope controller (Nanoscope IIIa, Digital Instruments). The photoluminescence could also be directed to a spectrometer via a remote-controlled flip-mirror. The spectrometer then dispersed the PL onto a liquid nitrogen cooled charge-coupled device (CCD) camera.

All NSOM tips used throughout this study were homemade using a commercial fiber puller ( $\mathrm{P} 2000$, Sutter Instruments) equipped with a $\mathrm{CO}_{2}$ laser. Fiber pulling of a $1 \mathrm{~m}$ single-mode optical fiber (F-SA, Newport) resulted in typical tip lengths of about 800 $\mu \mathrm{m}$. Within $1 \mathrm{~h}$ after pulling, a $90 \mathrm{~nm}$ thick layer of aluminum was evaporated onto the sides of the tips. This resulted in a very good coating quality with no side pinholes in the majority of tips. Aperture sizes of these tips were usually less than $100 \mathrm{~nm}$ in diameter. All tips were used within less than 1 month after fabrication. All tips were glued in glass capillaries and held in a $1 / 8$ " diameter piezo tube that provided the dither motion for 
shear force tip-sample distance control. For shear force detection, the beam of a $785 \mathrm{~nm}$ diode laser was focused on the very end of the tip. The diffracted beam was then projected onto a segmented photodiode. The 10x preamplified signal of the photodiode was fed into a lock-in amplifier and its $\mathrm{R}^{*} \cos (\theta)$ output was used as feedback signal, where $\mathrm{R}$ is the amplitude of the signal and $\theta$ the phase with respect to the reference. This scheme provided a hovering motion of the tip at typically $5 \mathrm{~nm}$ distance between tip and sample.

MEH-PPV thin films were prepared under ambient conditions from a MEH-PPV/Toluene solution with a concentration of $1 \mathrm{~g} / \mathrm{ml}$. Toluene, as a non-polar ("poor") solvent for MEH-PPV, is assumed to form aggregates already in solution ${ }^{16}$. Spin casting of a $20 \mu 1$ droplet on clean cover glass rotating at $1500 \mathrm{rpm}$ resulted in a film thickness of $20 \mathrm{~nm}$. Film thicknesses of each film were determined independently by scratching a center part of the film with the edge of a razor blade and subsequent step height measurement on an atomic force microscope.

\section{Results and Discussion}

Fig. 1a shows a $20 \times 20 \mu \mathrm{m}^{2}$ PL image of a $20 \mathrm{~nm}$ thick MEH-PPV film.

The black square in the middle of the image and the black bar below it are parts of the sample that were previously scanned. The PL in these areas is significantly reduced due to photo-oxidation. Photo-oxidation results in the creation of carbonyl groups that efficiently quench the $\mathrm{PL}^{17}$. The freshly imaged part of the sample reveals a highly inhomogeneous PL intensity. The sample is composed of PL "hot spots" with a spherical to slightly ellipsoidal shape and diameters of $100-500 \mathrm{~nm}$. As shown in fig. 3, these spots are not distinguishable by their topography from parts that show lower PL intensity. A detailed study of the photo-bleaching dynamics showed that the reduction in PL intensity is exponential with similar time constants for hot spots and background. This can be seen e.g. from the series of images in fig. 2a-d. These images depict a time series of subsequent scans of the same sample location (but different from fig. 1a) with an imaging time of 14 minutes per image. The relative intensities of bright and dark areas of the sample decrease at the same rates. If the composition of hot spots and background were different (e.g. hot spots: non-aggregated bubbles of MEH-PPV within an aggregated background or vice versa), one would expect a significant difference in bleaching dynamics due to the different photochemistry.

To further investigate aggregate formation in MEH-PPV thin films, PL images of smaller scan size using a PL color separation scheme were taken. 
Images of the same sample area were acquired, where the emission in the spectral range from $530 \mathrm{~nm}-605 \mathrm{~nm}$ and $620 \mathrm{~nm}-750 \mathrm{~nm}$ was used to create PL images. The purpose of separating the emission at about $610 \mathrm{~nm}$ was to separate the emission of intrachain excited singlet states ("excitons") which is predominant in the blue wavelength range from the broadband red-shifted emission of interchain states ("charge-transfer exciton", excimer) with an emission peak at about $720 \mathrm{~nm}$. If spatial localization (formation of domains) of aggregated species on the order of $50 \mathrm{~nm}$ or more would occur, they should be spatially distinguishable in their emission from the pure exciton-like emitting species ${ }^{3}$. Fig. 3a-c shows the topography and PL emission intensity below and above $610 \mathrm{~nm}$ of a $6 \times 6 \mu \mathrm{m}^{2}$ MEH-PPV thin film, respectively. The topography image (Fig. 3a) shows the existence of condensed MEH-PPV phases with a size distribution of a few $10 \mathrm{~nm}$ to about $1 \mu \mathrm{m}$ and heights between $10-20 \mathrm{~nm}$. The main PL emission, however, again stems from hot spots, which are parts of the sample that are not significantly expressed in their topography. Furthermore, the spatially resolved PL intensity below and above 610 $\mathrm{nm}$ (Fig. 3b,c) shows no striking differences. The intensity ratios of hot spots to background in both wavelength ranges is the same. This, together with the previously discussed results, leads us to the conclusion that aggregates are uniformly distributed throughout the thin film.

Near-field optical spectroscopy was performed to further study the nature and distribution of aggregates in thin films. While holding the tip steady above a fixed sample portion, PL spectra with $5 \mathrm{~s}$ integration time were obtained from a $20 \mathrm{~nm}$ thick MEH-PPV thin film. With a typical aperture diameter of $100 \mathrm{~nm}$ this results in a probe volume of roughly $210^{-}$ ${ }^{19} 1$. Fig. 4 shows a sequence of $3 \mathrm{PL}$ spectra taken at the times indicated in the figure. These 3 spectra were chosen from a continuous time series of spectra with an integration time of $5 \mathrm{~s}$ per spectrum. The overall photo-bleaching dynamics are exponential with a time constant of $40 \mathrm{~s}$ when illuminated with a near-field power density of $130 \mathrm{~W} / \mathrm{cm}^{2}$ at $514.5 \mathrm{~nm}$. The spectrum taken at 0 s shows a similar vibrational structure to the far-field spectrum of the same thin film in fig. $1 \mathrm{~b}$. After a few seconds of continuous illumination by the tip, however, the intensity of the first vibrational peak is significantly more reduced than that of the second peak. If the second peak were of purely vibrational nature, it's intensity reduction would be correlated to the decrease shown in the first peak. Since the reduction occurs at different rates, this leads us to the conclusion that the film consists of more than one emissive species, presumably pristine and aggregated chains. The faster intensity decrease of the first peak suggests that due to their different photochemistry, pristine chains are predominantly affected by photo-bleaching. This spectral bleaching behavior is independent of sample position which also supports our conclusion of a uniform distribution of aggregates in the film. 


\section{Conclusions}

Near-field optical microscopy and spectroscopy has been used to study the aggregation quenching in thin films of MEH-PPV. No characteristic spectral features of aggregatelike emission in thin films could be spatially isolated. This result suggests, that the size of aggregates in thin films must be smaller than the resolution limit of NSOM of roughly 50 $\mathrm{nm}$ in our case. Furthermore, the distribution of aggregates appears to be very uniform. Local photobleaching dynamics of ultra-small probe volumina suggests that at least two emissive species are present in such thin films. These results imply that more information on the formation of aggregates, their photochemistry, and how aggregation can be prevented can be obtained by single-molecule spectroscopy of isolated aggregates composed of one or only few molecules. Such experiments are currently under way.

\section{Acknowledgements}

The authors wish to express their thanks to Rachel Jakubiak and Lewis Rothberg, University of Rochester, for the gift of samples and many stimulating discussions. Work at LLNL was funded by LLNL's Laboratory Directed Research and Development Program under the auspices of the U.S. Department of Energy under contract no. W7405-ENG-48.

\section{References}

[1] R.H. Friend, R.W. Gymer, A.B. Holmes, J.H. Burroughes, R.N. Marks, C. Taliani, D.D.C. Bradley, D.A. Dos Santos, J.L. Bredas, M. Logdlund, W.R. Salaneck, Nature 397, 121(1999)

[2] L.J. Rothberg, M. Yan, F. Papadimitrakopoulos, M.E. Galvin, E.W. Kwock, T.M. Miller, Synth. Met. 80, 41(1996)

[3] R. Jakubiak, C.J. Collison, W.C. Wan, L.J. Rothberg, B.R. Hsieh, J. Phys. Chem. A 103, 2394(1999)

[4] R.C. Dunn, Chem. Rev. 99, 2891(1999)

[5] P.F. Barbara, D.M. Adams, D.B. O'Connor Ann. Rev. Mat. Sci. 29, 433(1999)

[6] L.A. Nagahara, H. Tokumoto, J. Vac. Sci. Technol. B 14, 800(1996)

[7] J.W. Blatchford, T.L. Gustafson, A.J. Epstein, D.A. Vanden Bout, J. Kerimo, D.A. Higgins, P.F. Barbara, D.-K. Fu, T.M. Swager, A.G. MacDiarmid, Phys. Rev. B 54, R3683(1996)

[8] J.A. DeAro. K.D. Weston, S.K. Buratto, U. Lemmer, Chem. Phys. Lett. 277, 532(1997)

[9] J.A. DeAro, U. Lemmer, D. Moses, S.K. Buratto, Synth. Met. 101, 300(1999)

[10] P.K. Wei, Y.I. Lin, W.S. Fann, Y.Z. Lee, S.A. Chen, submitted 
[11] J.A. DeAro, D. Moses, S.K. Buratto, Appl. Phys. Lett. 75, 3814(1999)

[12] J.A. DeAro, R. Gupta, A.J. Heeger, S.K. Buratto, Synth. Met. 102, 865(1999)

[13] S. Webster, D.A. Smith, D.N. Blatchelder, D.G. Lidzey, D.D.C. Bradley, Ultramicroscopy 71, 275(1998)

[14] R. Stevenson, M. Granstrom, D. Richards, Appl. Phys. Lett. 75, 1574(1999)

[15] P.K. Wei, J.H. Hsu,W.S. Fann, Synth. Met. 102, 1209(1999)

[16] T.-Q. Nguyen, V. Doan, B.J. Schwartz, J. Chem. Phys. 110, 4068(1999)

[17] M. Yan, L.J. Rothberg, F. Papadimitrakopoulos, M.E. Galvin, T.M. Miller, Phys. Rev. Lett. 73, 744(1994)

\section{Figure captions}

Fig1. Figure 1. a) Photoluminescence image of a $20 \mathrm{~nm}$ thick MEH-PPV film. The black square in the center of the image was imaged previously and shows reduced luminescence due to photo-oxidation. b) Far-field photoluminescence spectrum of the same MEH-PPV film exited at $514.5 \mathrm{~nm}$. Inserted is the chemical formula for MEH-PPV.

Fig.2 Figure 2. a)-d) Times series of subsequent photoluminescence images of a similar film as in fig. 1. Each image had an acquisition time of 14 minutes. Images sizes are $10 \mathrm{x}$ $10 \mu \mathrm{m}^{2}$.

Fig3. Figure 3. a) Topography, b) photoluminescence below $605 \mathrm{~nm}$, and c) photoluminescence above $620 \mathrm{~nm}$ for the same film as in fig. 1 but at a different location.

Fig.4 Figure 4. Near-field spectra of the same film as in fig. 1. Each spectrum was taken at the times indicated in the figure with an integration time of $5 \mathrm{~s}$. Note the faster reduction of the first peak as compared to the second peak. 

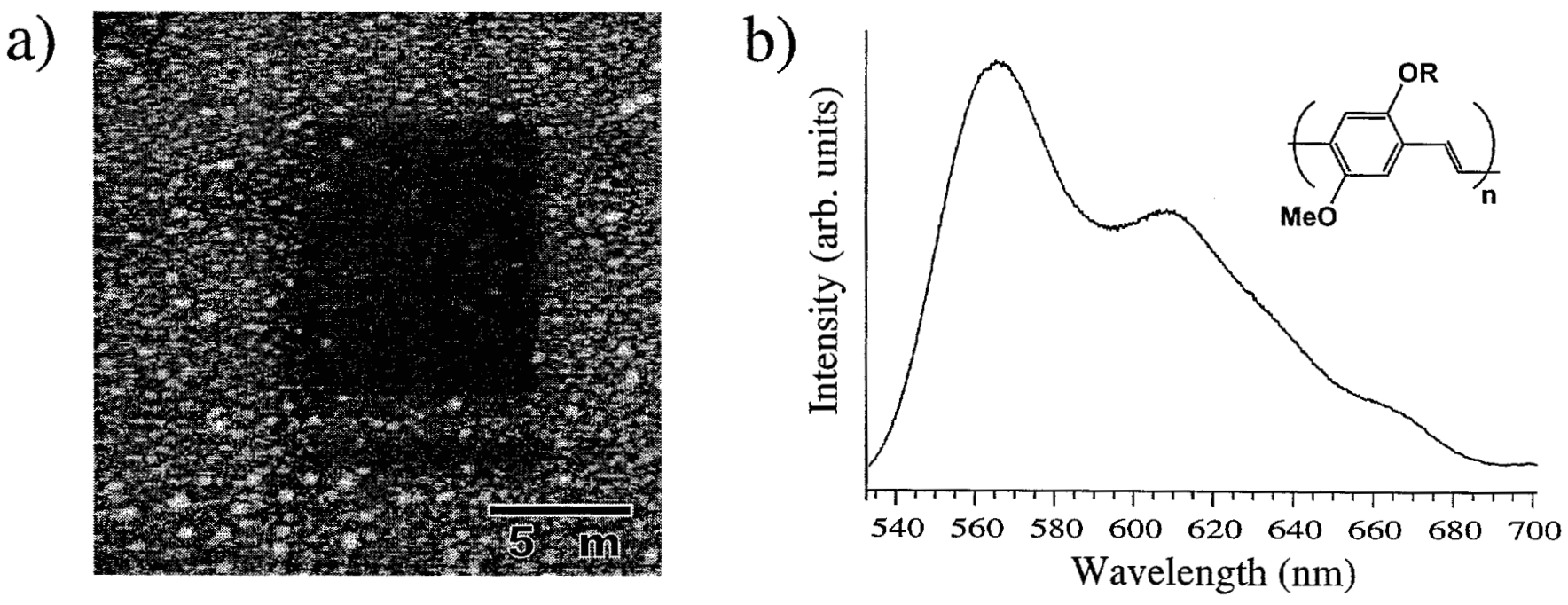

Huser and Yan, Fig. 1 

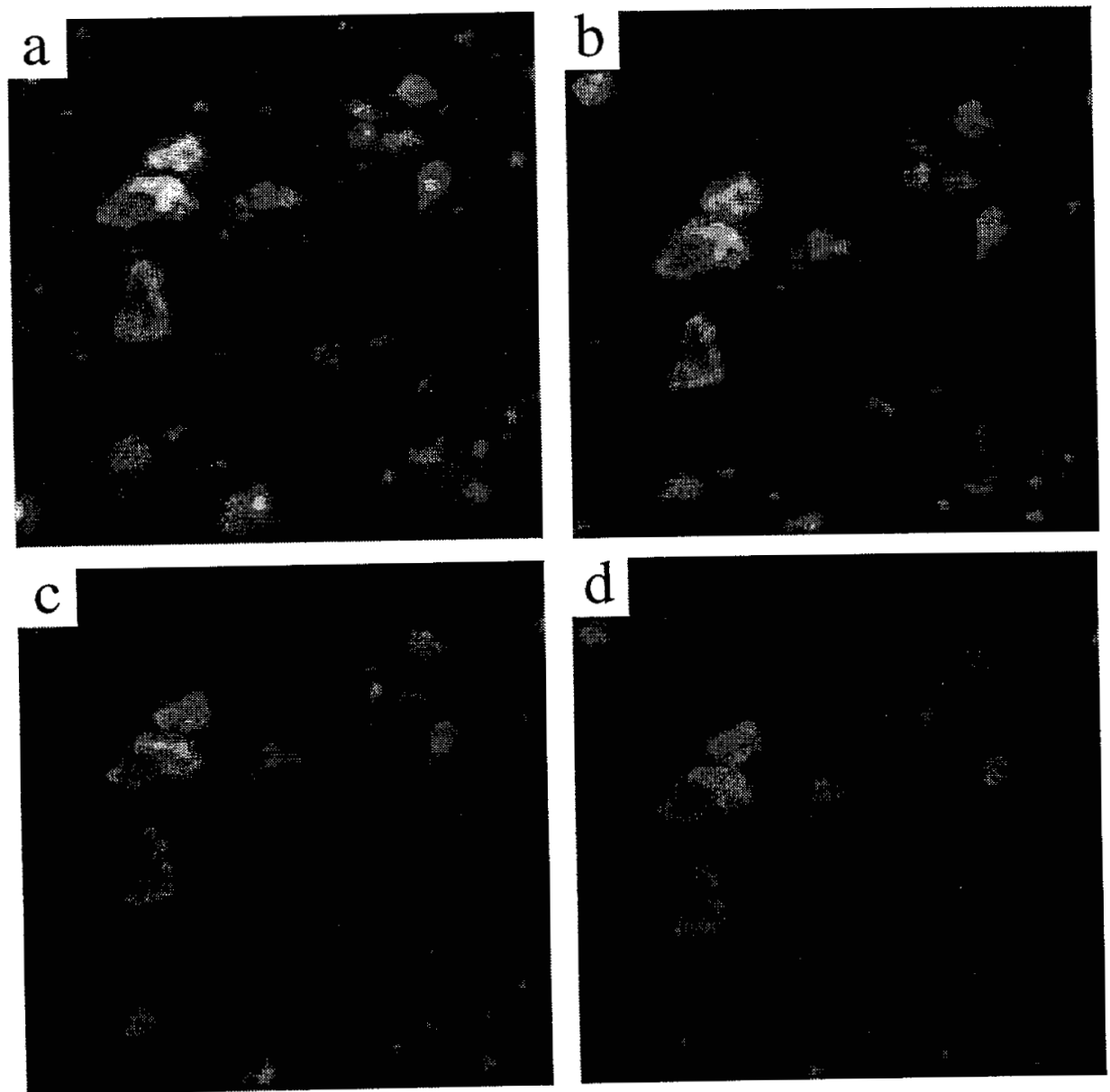

Huser and Yan, Fig. 2 
a)

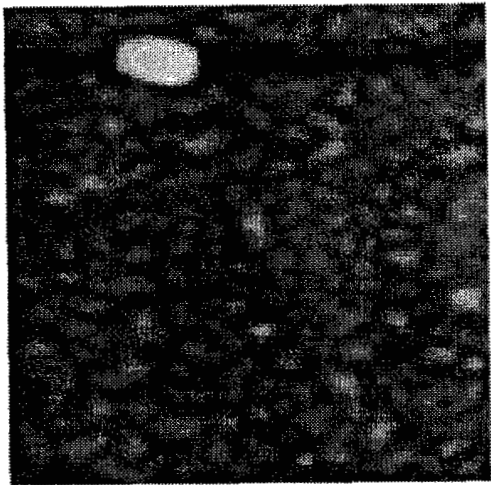

$2 \mathrm{~m}$ b)

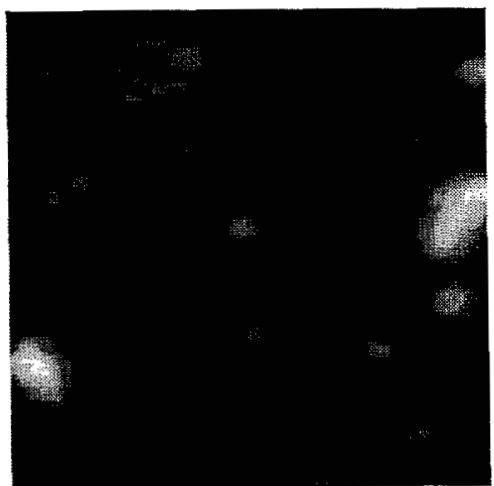

Emission $<605 \mathrm{~nm}$ c)

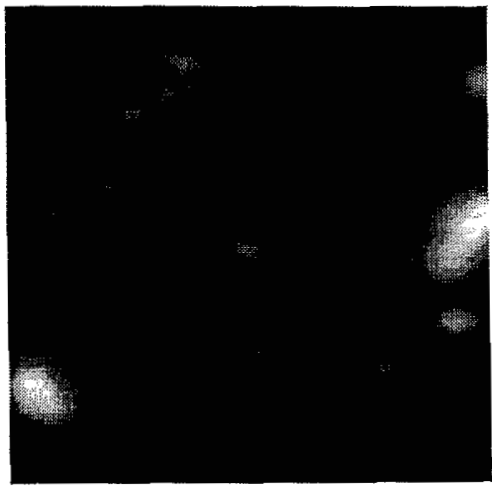

Emission $>620 \mathrm{~nm}$ 


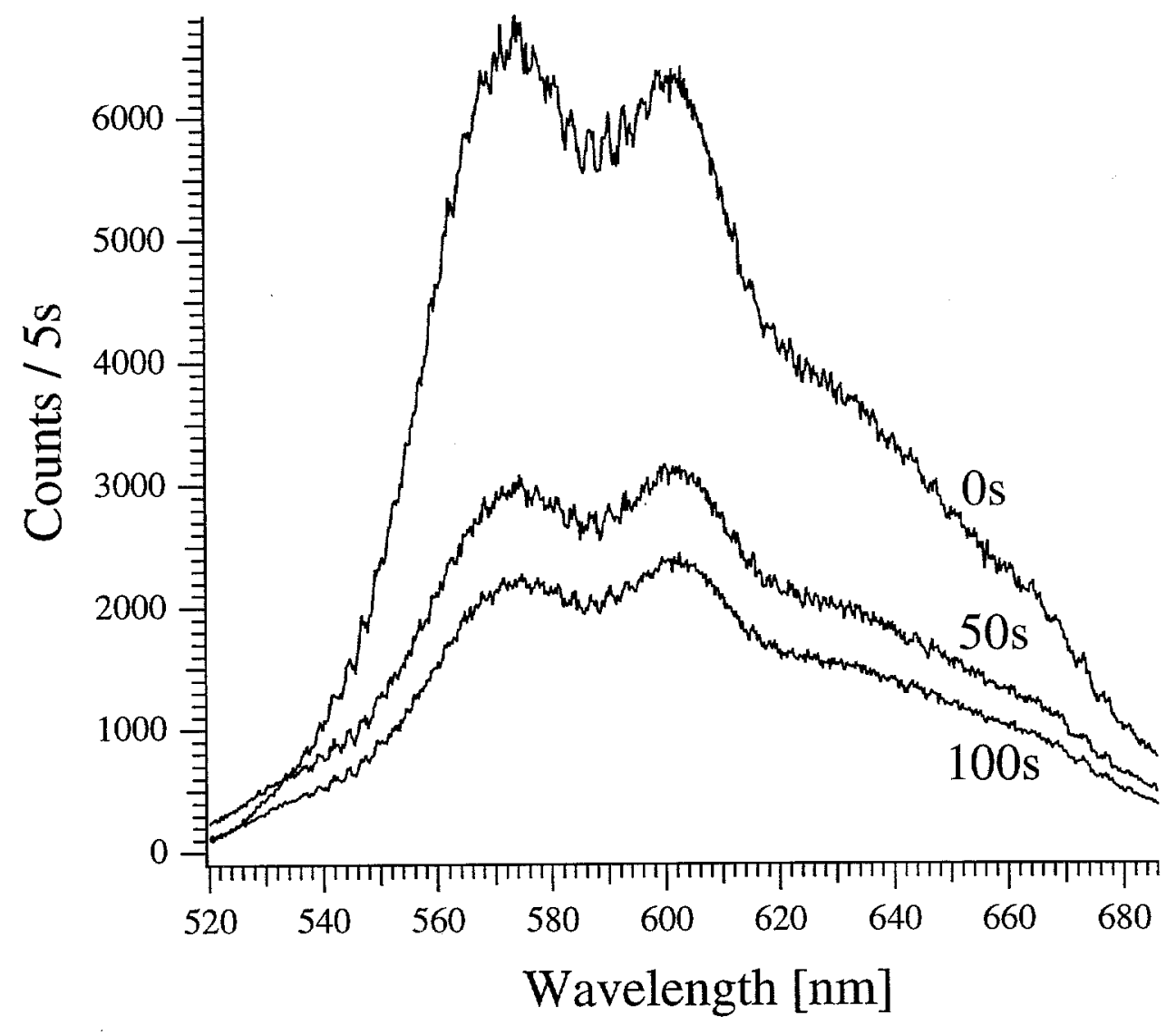

Huser and Yan, Fig. 4 